\title{
A função política dos discursos sociais e suas implicações sobre a biografia
}

\author{
The political function of social discourses and their \\ implications for biography
}

Resumo: O presente artigo tem como objetivo realizar uma discussão acerca da função política dos discursos sociais, bem como de suas implicações para a construção biográfica. A análise parte do resultado de duas pesquisas que tiveram como objeto de estudo dois tipos de atividades profissionais: catadores de resíduos e chefes de gabinete. Ambos os estudos possuem caráter qualitativo, e foram conduzidos a partir do método de entrevistas narrativas biográficas, com a utilização da reconstrução biográfica de caso como método de análise. A partir de conceitos formulados pelos sociólogos Pierre Bourdieu e Alfred Schütz, discutimos de que forma os entrevistados instrumentalizam discursos sociais a fim de legitimar suas práticas, bem como construir uma identidade positiva de si mesmos, com impacto sobre a biografia.

Palavras-chave: Discursos sociais; Narrativas biográficas; Biografia; Catadores; Chefes de Gabinete.

\begin{abstract}
This article aims to conduct a discussion about the political function of social discourses, as well as its implications for the biographical construction. The analysis is based on the results of two different research projects: a study with waste pickers and another with chiefs of staff. Both studies were conduct with qualitative methods, more specifically with the methods of biographical narrative interviews and biographical case reconstruction. Based on concepts formulated by sociologists Pierre Bourdieu and Alfred Schütz, we discuss how the interviewees instrumentalize social discourses in order to legitimize their practices, as well as build a positive identity of themselves, with impact on the biography.
\end{abstract}

Key-words: social discourses, biographical narratives, biography, waste pickers, chiefs of staff

\section{Introdução}

Quem nunca escutou expressões como: "não me envolvo em política", "não gosto de política" ou mesmo "política não se discute"? Podem ser múltiplas as intenções que permeiam estas frases, como o afastamento destas temáticas a fim de evitar diferentes tipos de conflitos, falta de informação, assim como a simples falta de interesse. Independentemente da intenção de cada um que as verbaliza, expressões como essas demonstram, sobretudo, a tentativa de exclusão do político no dia a dia. 
Já na primeira tentativa de refletir de forma mais abrangente sobre as possíveis manifestações do político nas biografias, nos ocorrem múltiplos exemplos: a participação de pessoas em movimentos políticos e sociais, protestos, reuniões de condomínio, reuniões de pais, conversas cotidianas, além de outros tipos de ocorrências relacionadas direta ou indiretamente ao universo de caráter político.

Em tempos de fortes embates políticos e de cunho ideológico, no Brasil e em outros países, percebemos que os elementos políticos da vida diária, ou seja, o ato de nos posicionarmos sobre algum assunto com vistas à legitimação, se apresentam em todas as biografias, indiferentemente da presença ou ausência de envolvimento político, diferenciando-se apenas na frequência, no modo como são experienciados, interpretados, assim como na maneira como são relatados através dos discursos individuais.

Por essa perspectiva, o presente estudo objetiva discutir a função política dos discursos sociais e suas implicações sobre a biografia de seis trajetórias distintas, exploradas em estudos anteriores, destacando o fato de que as biografias surgem em contextos político-sociais, estando os sujeitos, portanto, expostos a manifestações relacionadas ao meio social que fazem parte. Vale destacar que a originalidade da discussão se dá especialmente pelo fato de evidenciarmos de que formas grupos sociais tão distintos - como catadores de resíduos e chefes de gabinete - conseguem fazer igualmente uso de discursos sociais com vias a autolegitimação mesmo em contextos sociais tão desvantajosos, como é o caso, em especial, dos catadores de resíduos. Cientes de que não existe uma única forma de como o político se manifesta no biográfico, partir-se-á de questionamentos como: "de que forma os sujeitos assumem determinados discursos na interação social e que função encontramos nesses discursos?" e "de que forma esses discursos se manifestam sobre suas biografias?".

Para tanto, a discussão será conduzida da seguinte forma: a partir de autores como Pierre Bourdieu, mas também Alfred Schütz, gostaríamos de discorrer primeiramente sobre o principal conceito que fundamenta esta discussão: a função política dos discursos sociais, sua construção e aplicação na vida cotidiana. Tal importância se dá devido à, em princípio, despretensiosa, quase despercebida, mas corrente instrumentalização de determinados discursos no momento da entrevista com vias à legitimação. Logo, a compreensão dessa instrumentalização passa tanto por uma análise profunda da função dos discursos, como também por um entendimento de biografia que permita evidenciarmos os mecanismos de uma construção, em princípio, individual, mas com clara participação coletiva. No que concerne às possíveis divergências entre uma teoria de cunho estruturalista e outra interpretativa de orientação fenomenológica, importa ressaltar, desde o início, que Bourdieu produziu, em suas obras, duras críticas, tanto à fenomenologia3 ${ }^{3}$ quanto à abordagem da subjetividade e à pesquisa biográfica de modo geral ${ }^{4}$, e que, por outro lado, os teóricos da própria

\footnotetext{
3 Para mais, conferir a obra Meditações Pascalianas (BOURDIEU, 2001).

4 Num artigo intitulado "A ilusão biográfica”, Bourdieu (1986) considera a biografia, no campo científico, como uma espécie de "ilusão retórica", uma história de ficção, na qual o pesquisador entraria como mero cúmplice. Para ele, a biografia reforça a noção da existência como um relato coerente de uma sequência de acontecimentos com significado e direção, o que seria tentar compreender uma vida como uma série única e por si suficiente de acontecimentos sucessivos, tendo como vínculo único a associação à um sujeito, o que seria "quase tão absurdo quanto tentar explicar a razão de um trajeto no metrô sem levar em conta a estrutura da rede" (BOURDIEU, 1986, p. 189). Entretanto, alguns anos depois, Bourdieu chega até mesmo a rever essa crítica, mas sem formalizá-la (PAPE, 2009). Ele recebe um convite do governo francês para realizar um estudo sobre moradia na França, no qual ele aplica mais de 50 entrevistas de cunho biográfico, dando origem no ano de 1933 ao livro Misère du Monde (BOURDIEU, 2001).
} 
sociologia compreensiva, por voltarem-se para a interpretação subjetiva dos atores, também trazem críticas, em seus estudos, à teoria estruturalista de Pierre Bourdieu5. Convém assinalar, entretanto, que muito embora se tenha o conhecimento acerca dos pressupostos teóricos com bases e fundamentos tão distintos, o presente artigo não intenta explorar o debate frequente entre estrutura $x$ indivíduo no campo da sociologia, mas sim, trazer à luz os pontos de convergência de suas teorias sociais, destacando o seu potencial agregador.

Após a breve discussão dos conceitos, apresentaremos os resultados das pesquisas, bem como uma conclusão final que pretende sintetizar nossos principais achados. De maneira geral, podemos observar que os discursos sociais corroboram na sustentação das estruturas da biografia ${ }^{6}$ com argumentações, e justificativas que corroboram nos discursos legitimadores dos porquês de nossa ação. Dado que somos mais "políticos" do que imaginamos ser, e que isso traz à tona consequências para nossas trajetórias de vida, a análise dos discursos sociais dos entrevistados permite explorarmos, nesse sentido, a própria tomada de ação dos pesquisados, evidenciada através de seus discursos e do modo como são manifestados.

\section{Conceitos}

A partir de Rosenthal (2014), compreendemos biografia como o resultado de uma construção subjetiva, mas também coletiva e dual, sendo produto de um processo individual e coletivo ao mesmo tempo 7 . Isso significa dizer, que tudo que sabemos sobre nós e as ideias que construímos sobre nossa trajetória, são produzidas na relação com os outros num contexto espacial e temporal específico. Nossos entrevistados, quando relatam sobre seu nascimento, por exemplo, falam sobre nascimentos "normais", "sem complicações" ou "complicados", ou ainda de uma "infância normal" ou de uma "infância difícil". Essas e demais percepções são transmitidas aos indivíduos através de seus pares, como familiares, amigos, vizinhos, professores, etc., e vão orientando a maneira como esses passam a compreender a si e a suas trajetórias.

Para além da discussão sobre a construção ou origem das percepções sociais, nos interessa neste estudo, em especial, analisar a dinâmica que rege a aplicação dos discursos na vida cotidiana. Para o sociólogo Pierre Bourdieu (1989), a estruturação do mundo social está diretamente associada às práticas que buscam a sua manutenção. As diferentes forças que encontramos no campo social $^{8}$, exercidas pelas classes sociais e seu respectivo habitus ${ }^{9}$, mas também pelos dife-

\footnotetext{
5 A sociologia compreensiva pressupõe que o ator social não seria um mero internalizador de normas, valores e significados, mas sim um agente consciente e responsável pela adoção ativa de códigos normativos através da interpretação da realidade social (PARSONS, 1978 apud SANTOS, 2012). Para Santos (2012), admitir a existência de biografia implicaria, assim, em atribuir ao sujeito um status de ator que Bourdieu e seus seguidores não estariam dispostos a assumir.

6 Quando referimos a estrutura da biografia, trata-se da construção de sentido que os atores dão às suas trajetórias de vida a partir das experiências relatadas no ato da entrevista. É função do pesquisador buscar compreender o sentido que o entrevistado dá a essa trajetória a partir de uma análise acurada dos relatos.

7 Também ver Radenbach; Rosenthal (2012).

8 Campo social é uma abstração empregada por Pierre Bourdieu $(1989 ; 2007)$ para designar a sociedade. No campo social Bourdieu situa as diferentes classes sociais, bem como uma série de campos, que apresentam semelhantes regras de funcionamento.

9 O conceito de habitus possui centralidade na teoria de Bourdieu à medida que designa um sistema de disposições constituídas socialmente e que por sua vez constituem as práticas e ideologias de grupo (BOURDIEU, 2007). O habitus é a unidade de sentido
} 
rentes $\operatorname{campos}^{10}$ de atuação dos agentes sociais distribuídos nessas classes, estariam envolvidas em um jogo de disputa pelo monopólio da representação do mundo social. Os sistemas simbólicos $^{11}$ funcionariam, nesta disputa, como instrumentos de conhecimento e de comunicação dos objetos do mundo social, cumprindo "a sua função política como instrumentos de imposição ou de legitimação da dominação" (BOURDIEU, 1989, p. 10).

Aqui se destacam sistemas simbólicos como a linguagem. Discursos, expressões populares, jargões, conceitos científicos, entre outros, fazem parte dos instrumentos em oferta na própria linguagem e que tem o poder de legitimar práticas sociais. Em outras palavras, isso significa dizer, que os sistemas simbólicos são, usando outro conceito do autor, prescritivos, ou seja, são a definição (estrutura) da realidade social à medida que a definem (estruturam), possibilitando "o consensus acerca do sentido do mundo social" (BOURDIEU, 1989, p.10).

A partir do viés fenomenológico de Alfred Schütz (2004, 2018), trata-se de um consensus assegurado pela possibilidade do compartilhamento de um estoque de conhecimento socialmente construído, que "garante que aquilo, que eu sei, os outros também sabem", fazendo com que a experiência acabe por confirmar o conhecimento. Se a disputa pela determinação das representações do mundo social está reservada, segundo Bourdieu (1989), a um grupo seleto de pessoas (os dominantes), assim como para Peter Berger e Thomas Luckmann (2014) estaria localizada no domínio dos chamados especialistas ${ }^{12}$, é verdade que a legitimação dessas representações dependeria, sempre, da reprodução do seu sentido no campo social como um todo.

A aceitação do sentido pelos demais grupos e agentes sociais é viabilizado na teoria de Bourdieu $(1989,2007)$, entre outros fatores, por aquilo que ele chama de distinção. Em suas palavras, distinção corresponde à "diferença inscrita na própria estrutura do espaço social quando percebida segundo as categorias apropriadas a essa estrutura" (BOURDIEU, 1989, p. 144). Para além de uma ideia de distinção como a diferenciação com base no poder de determinação do "gosto" pelas classes dominantes em relação às dominadas a partir da distribuição desigual de capital econômico, cultural e social (BOURDIEU, 2007), gostaríamos de ressaltar a compreensão de distinção como toda forma de busca pela diferenciação socialmente aceita e desejada pelos sujeitos, a qual consiste, nas palavras de Bourdieu (1989, p. 144) na "procura da distinção - que pode marcar-se nas maneiras de falar ou na recusa a um casamento desigual - [a qual] produz separações destinadas a serem percebidas ou, melhor, conhecidas e reconhecidas como diferenças legítimas, quer dizer, na maior parte dos casos, como diferenças de natureza" (BOURDIEU, 1989).

\footnotetext{
que une as classes sociais aos estilos de vida.

10 Assim como o campo social, também os diferentes campos (ciência, direito, política, economia, religião, entre outros), se caracterizam para Bourdieu $(1989 ; 2007)$ pela presença de determinados interesses, pelos quais os agentes situados no campo se encontram em constante disputa, bem como pela sua autonomia em relação aos demais campos.

$"$ Os sistemas simbólicos funcionam para Bourdieu como artefatos culturais, instrumentos responsáveis pela comunicação e o compartilhamento de conhecimento, sendo, em si autoexplicativos. São eles a arte, a ciência, o mito, a língua, os discursos sociais, entre outros (BOURDIEU, 1989).

12 Para Berger e Luckmann (2014) os especialistas são os indivíduos que dominam o conhecimento especializado, bem como detém a legitimação pelo seu compartilhamento a partir de determinados rituais institucionais.
} 
Se por um lado a determinação das categorias que definem o mundo social está reservada, segundo Bourdieu (1989), a grupos específicos como os dominantes e os especialistas, por outro lado, também os dominados ou os laicos fazem uso dessas categorias nas estratégias diárias de legitimação de suas práticas e de sua identidade; ou seja, na disputa pela determinação dos sentidos na interação social. Podemos, portanto, encontrar diferentes sentidos para as mesmas categorias, a depender do contexto no qual são instrumentalizadas. A reciclagem de resíduos pode, por exemplo, apresentar um sentido totalmente distinto dependendo do contexto e dos agentes que a praticam. Enquanto no âmbito de um grupo de empresários ela possa significar "progresso" ou "prática sustentável", quando realizada num grupo de catadores de rua ela pode ser percebida como "ilegal" ou "insalubre". O que nos importa destacar não é o fato se tal atividade é sustentável, insalubre ou não, mas sim evidenciar de que forma e quando os sujeitos fazem uso desses discursos.

A partir de Bourdieu, poderíamos argumentar que os sujeitos tenderão, como efeito da relação entre campo e habitus, a jogar o jogo conforme as regras do próprio campo. Uma vez internalizadas, tais práticas estão sujeitas a certo automatismo. Possivelmente é aqui que reside uma diferença crucial entre a noção de Bourdieu sobre o que ele chama de "sentido prático" da ação e a concepção desenvolvida por Schütz sobre o que Max Weber chamava de sentido subjetivamente visado da ação (DUKUEN, 2010). Para Schütz, o jogo não seria possível somente como mera resposta do corpo condicionado a um habitus, mas sim da possibilidade de reflexão do sujeito e da sua possibilidade de escolha a partir de um sistema de relevância socialmente construído. Nesse sentido, acreditamos que Schütz nos ajuda a compreender melhor a possibilidade de agência dos sujeitos dentro de contextos fortemente determinados e, muitas vezes, extremamente desvantajosos. Ao contrário da crítica realizada por Bourdieu à fenomenologia social, a perspectiva teórica e metodológica schütziana nos parece muito mais desafiadora para o cientista social diante da ação social, visto que capturar o resultado da dinâmica que possibilita não somente a manutenção, mas também a criatividade e a inovação, torna-se um trabalho muito mais árduo.

Por fim, nos interessa aqui destacar o fato de que as categorias do mundo social são o tempo todo instrumentalizadas pelos sujeitos em seu próprio favor, fazendo com que seu sentido esteja o tempo todo em disputa na interação social, como parte das lutas simbólicas pela produção e imposição da visão do mundo. Esta "luta, ao mesmo tempo teórica e prática pelo poder de conservar ou transformar o mundo social conservando ou transformando as categorias de percepção deste mundo" (BOURDIEU, p. 142, 1989) é uma prática reservada pelo autor, em especial, ao campo político e aos seus agentes, considerados profissionais da representação por excelência. A função política-legitimadora que exercem os sistemas simbólicos não se limita, porém, ao campo político, e sim se estende às práticas dos agentes do campo social como um todo, os quais fazem uso da linguagem e dos discursos sociais nas suas práticas diárias a fim de se legitimar (BOURDIEU, 1989).

Retomando o conceito de biografia aqui exposto, a linguagem, bem como os discursos sociais, tem um papel importante na construção biográfica. Se a partir de Rosenthal e Fischer-Rosenthal (1997) a possibilidade de se ter uma biografia, ou seja, a possibilidade de se refletir sobre a própria existência, é considerada uma construção humana das sociedades modernas, ela também configura uma eficiente forma de controle social que buscará sempre co-determinar essa existência. Diante de tal ambigui- 
dade - reflexão e controle - própria das biografias, argumentamos com base na análise de nossas entrevistas, que os discursos sociais, ao cumprirem um papel legitimador, também desempenham um papel estabilizador e "normalizador", visto que, ao transmitirem valores, regras, desejos e emoções, dão sentido à trajetória dos sujeitos, bem como as suas construções identitárias. De que formas essa ambiguidade se manifesta e como ela é "resolvida" pelos biografados é o que veremos a seguir.

\section{Resultados das pesquisas desenvolvidas com catadores e chefes de gabinete}

Os principais resultados obtidos nas pesquisas anteriormente referenciadas serão apresentados nesta seção. A partir da análise das entrevistas com catadoras e com chefes de gabinete, serão explorados elementos discursivos com foco na forma como os entrevistados apresentam esses discursos tendo como base a reconstrução de suas biografias através da análise interpretativa. A análise conjunta de um material empírico coletado em estudos com grupos sociais tão distintos se mostrou especialmente viável devido ao uso do método de entrevistas narrativas biográficas e do método de reconstrução biográfica de caso em ambas as pesquisas ${ }^{13}$. De maneira geral trata-se de métodos que possibilitam, respectivamente, a apreensão e a análise sistemática de discursos sociais no contexto biográfico, mantendo a ordem e a maneira como foram formulados pelos biografados no ato da entrevista. Especialmente a análise textual das entrevistas, que consiste na distinção do conteúdo textual em passagens argumentativas, narrativas ou descritivas possibilitou compreendermos de que forma os discursos trazidos pelos nossos interlocutores se relacionam com suas estratégias biográficas ${ }^{14}$.

\section{A interpretação da catação pelos catadores}

As duas reconstruções de caso e os resultados que serão aqui apresentados foram obtidos a partir de entrevistas biográficas com Aline e Vanessa, realizadas em suas residências ${ }^{15}$. Aline e Vanessa viviam em bairros populares, marcados, especialmente, pela forte presença de catadores de resíduos, organizados de forma individual ou coletiva. As entrevistas de Aline e Vanessa foram conduzidas por diferentes entrevistadoras, tendo temas de pesquisa bastante distintos como pano de fundo: enquanto a entrevista de Aline foi realizada no contexto da proposta de pesquisa aqui apresentada, a entrevista de Vanessa foi conduzida a partir do tema "remoções compulsórias". As entrevistadas conheciam os interesses de pesquisa de suas entrevistadoras, mesmo que de forma superficial. Estas informações, embora apresentadas de maneira resumida, são fundamentais para compreendermos a influência das circunstâncias da situação de entrevista sobre a fala das entrevistadas.

\footnotetext{
13 Mais detalhes sobre os métodos ver Rosenthal, 2014.

14 Estratégia biográfica é um conceito bastante usado na pesquisa biográfica interpretativa e faz referência à forma como os sujeitos apresentam suas trajetórias de vida seguindo um determinado interesse de apresentação. Mas informações ver Rosenthal (2014).

15 O presente estudo foi realizado no âmbito de um projeto de mestrado sobre a interpretação de catadores de resíduos sobre a catação na cidade de Porto Alegre (RINALDI, 2018).
} 
No que concerne ao contexto vigente à época da realização das entrevistas, é importante destacar que este era bastante singular para os catadores que atuavam em Porto Alegre: desde 2008 os catadores de resíduos vêm lidando com os efeitos que a Lei n. $10.531^{16}$, que proíbe o uso de carrinho e carroça na zona urbana da cidade, está causando na organização do seu trabalho e da sua vida financeira. Desde a regulamentação da lei em 2010, a prefeitura municipal realiza ações de restrição ao uso de carrinho e carroça, dificultando o cumprimento de suas rotinas de trabaIho, visto que esses, em sua maioria, vivem e trabalham na região urbana da cidade, com grande concentração da atividade nas regiões centrais. Em contrapartida às ações de restrição, o poder municipal ofereceu uma indenização aos catadores pela entrega dos carrinhos, carroças e cavalos, além da possibilidade de realização de cursos de qualificação em diferentes campos profissionais. Sem ter atingido suas metas de inclusão desses trabalhadores no circuito de trabalho, catadores de resíduos seguem trabalhando, em sua maioria, de modo informal na atividade, num ambiente de insegurança sobre o futuro da sua fonte de renda e com investimentos tímidos por parte do poder público para o reconhecimento e formalização de suas práticas.

Além da lei de restrição, com efeitos diretos sobre o dia-a-dia dos catadores de resíduos, três eventos nos ajudam a localizar a situação dos catadores no contexto social mais amplo. Primeiramente, refere-se a Lei n. 12.305, que institui, no ano de 2010, o Plano Nacional de Resíduos Sólidos (PNRS) (BRASIL, 2010). Essa lei buscou organizar a cadeia da reciclagem, identificando e responsabilizando todos os agentes nela envolvidos: os produtores dos resíduos (indústria e consumidores), os catadores, o Estado, os comerciantes, bem como a indústria do reaproveitamento. Na sua formulação participaram, além de parlamentares e técnicos, integrantes do Movimento Nacional dos Catadores(as) de Materiais Recicláveis (MNCR), os quais exigiam a integração de catadores no ciclo da reciclagem (CAMPANI, 2016). Assim, chegamos no segundo elemento que também situa os catadores de resíduos no mapa social: desde o ano de 2001, os catadores possuem o apoio do Movimento Nacional de Catadores de Resíduos (MNCR), uma organização que atua, principalmente, na instância política, tentando influenciar decisões de grupos políticos através de leis e decretos no que tange à institucionalização e legitimação do trabalho dos catadores. Uma das principais críticas feitas à organização faz referência ao fato de ela representar somente os catadores organizados em coletivos, deixando uma grande parte dos catadores ainda organizados de forma individual e/ ou que se encontram em empreendimentos familiares fora do processo de legitimação da atividade e, por isso, desassistidos. Além disso, diz-se que seu impacto sobre a politização dos catadores é de curto alcance, além de, frequentemente, bastante seletiva.

Por fim, um terceiro evento, importante para compreendermos o contexto social dos catadores e, especialmente, de nossas entrevistadas, faz referência às primeiras associações de catadores em Porto Alegre, fundadas com a ajuda de entidades religiosas entre os anos de 1985 e 1990 (MICHELOTTI, 2006; SILVA; NASCIMENTO, 2017). Essas associações são responsáveis pela triagem e venda dos resíduos à indústria do reaproveitamento. O dinheiro da venda é repassado aos trabalhadores da associação. De 1990 até aos tempos atuais, a cidade já registra a presença de cerca de dezessete

16 Mais informações ver PORTO ALEGRE (2010). 
associações, denominadas "Unidades de Triagem" (PORTO ALEGRE, 2019). Essas unidades vêm trabalhando com cada vez mais intensidade em cooperação com o poder municipal, à medida que este último é o responsável, atualmente, por fornecer os resíduos para as unidades através da coleta seletiva, bem como por prestar apoio financeiro para o custeio de suas instalações.

Esses, portanto, são alguns elementos que tecem o pano de fundo que assemelha e une, mas também diferencia, os sujeitos que vivem da reciclagem de resíduos em Porto Alegre. Une, porque encontramos semelhantes experiências e discursos das entrevistadas ao apresentarem o seu trabalho e a si mesmas; mas também diferencia, dada a complexidade de suas socializações, conforme discutiremos a seguir.

Ao que concerne à maneira como as entrevistadas apresentam a catação, foi possível evidenciar que, enquanto Aline apresenta a catação como uma forma específica de consumo, ou seja, um consumo baseado, especialmente, no reaproveitamento de bens duráveis, Vanessa fala sobre a catação como uma atividade laboral que lhe rendeu, além da sobrevivência, uma forma de reconhecimento social. Se tentarmos reconstruir brevemente a forma como estruturam ${ }^{17}$ suas falas sobre a catação e, em certa medida sobre si mesmas, chegaremos a algumas conclusões pertinentes.

Iniciando por Aline, veremos que esta menciona o prazer que sente em trabalhar na atividade desde o início da entrevista ${ }^{18}$, usando expressões como "eu gosto de catar" e "catar é bom", repetidamente, e em diferentes momentos durante as mais de três horas de entrevista. Nas primeiras horas, Aline esteve atenta em não só falar, mas também "provar" o valor que a catação tinha em sua vida, convidando a entrevistadora para uma visita guiada pelas peças de sua casa, apresentando tudo que havia encontrado ou ganho na reciclagem. Usamos a palavra "provar" ao invés de mostrar, visto que havia uma tentativa de convencimento sobre a importância daquele trabalho em sua vida. Em nosso segundo encontro, ao final da entrevista, Aline surpreende sua interlocutora com a afirmação de que tem vergonha de catar e que, diante da sua nova realidade, como possível integrante da instituição social que prestava serviços de assistência no seu bairro de moradia, "terá" que deixar a reciclagem. A reconstrução de sua biografia permitiu observar que, mesmo as passagens com teor positivo referente à catação eram, frequentemente, acompanhadas de lembranças retratadas como experiências de sofrimento: "eu gosto de catar lixo, por causa que né, eu já cresci assim né, a gente tinha que comer comida do lixo pra poder sobreviver". Se ainda na infância, Aline relata ter visto na catação uma atividade que lhe foi imposta pela mãe, a qual envolvia sujeira e risco de contaminação, na adolescência ela é retratada pela entrevistada como uma possibilidade, já que estava acostumada a realizá-la e percebia que, diferente da mãe, outras pessoas obtinham sucesso na atividade, tendo nela, assim, a chance de garantir a alimentação do filho. Ao longo dos anos, a catação foi ganhando um papel importante, principalmente, na obtenção de bens duráveis. Se por

\footnotetext{
17 Embora a ideia de "estrutura" possa sugerir ao leitor que se trata de uma construção consciente de conteúdo e forma sobre "a catação" pelo entrevistado, é necessário ressaltar que se trata de uma análise das estruturas de uma construção latente de sentido com base no que chamamos de motivos manifestos, ou seja, em cima daquilo e da maneira como o entrevistado relata o objeto em questão. Mais detalhes ver Rosenthal (2014).

18 É importante lembrarmos que se trata de uma entrevista biográfica, com uma pergunta inicial com diferentes graus de abertura. Nesta entrevista, solicito que a entrevistada fale sobre sua vida, levando em consideração as diferentes fases da vida, iniciando pelo seu nascimento.
} 
um lado, ela permitiu o consumo, por outro, ela também foi apresentada como um "passatempo", um motivo de vergonha por não se enquadrar mais no seu estilo de vida.

Em linhas gerais, a interpretação de Aline sobre a catação, assim como a de Vanessa, deve ser compreendida como um processo, no qual experiências junto à família, aos vizinhos e demais catadores da região foram moldando, no processo de socialização, a forma como enxergam e dão significado a essa atividade. Nesse processo, podemos observar como Aline faz uso de uma série de discursos, principalmente aqueles de cunho moral voltados à catação como um meio para o seu sustento e do filho; uma atividade que permite, além do sustento, o consumo, mas que, ao mesmo tempo, gera vergonha e, nesse sentido, também é impróprio. Esses diferentes discursos, refletem a complexidade de suas experiências e, consequentemente, do caráter ambíguo de sua interpretação sobre a atividade, embora a biografada apresente a clara intenção de ressaltar os benefícios do trabalho, defendendo a sua importância, em detrimento de algo que demonstra lhe causar grande desconforto: a ausência de identificação com a mesma.

Vanessa, por sua vez reserva ainda mais espaço para as experiências positivas com a catação do que Aline. Levando em consideração a maneira como ela apresenta o significado da catação desde a infância - atividade que tem início aos 10 anos de idade com o objetivo de ajudar a família financeiramente após a morte do pai -, Vanessa destaca o fato de a catação ter permitido que a família não passasse por dificuldades e fome, possibilitando o consumo através do reaproveitamento ou venda dos resíduos encontrados ou doados. Em nenhum momento da entrevista Vanessa traz possíveis aspectos negativos da atividade. Tal fato não significa que eles não existam, já que, possivelmente, Vanessa, assim como Aline e muitos outros catadores (DIAS, 2002), sentiu-se, em algum momento de sua vida constrangida por trabalhar na reciclagem de rua. O que nos importa aqui, é poder observar que a maneira como apresenta a catação faz parte de uma estratégia de valorização da atividade, bem como de si mesma e de suas capacidades como integrante tanto de uma família, quanto de um coletivo de catadores, os quais puderam, com sua ajuda, superar as adversidades decorrentes da escassez de recursos, assim como relata a entrevistada na seguinte passagem:

[...] tu tá puxando carrinho quando tu é criança tu tá te divertindo porque tu vê tanta coisa, tu ganha tanta coisa, tanta coisa, então tu faz aquele momento pra ti, entendeu, tu vive aquele momento, daí é diferente, é muito legal, eu acho que se tocasse de vivê esse momento de papelera eu queria vivê de novo, sabe, não tenho vergonha, todo mundo, onde tu trabalha, trabalho num galpão de reciclagem, com muito orgulho, não tenho vergonha do meu serviço, ah vamo fazê uma gravação lá, vamo fazê, vamo mostra, e não só eu, vamo mostrá o galpão intero, vamo fazê, é todos, não é só eu, só o Mauro, é um conjunto de seis pessoas, daí tem aqueles seis e tem mais vinte e poucos nas costa, porque são família, dependem dali de dentro, eu gosto tanto, eu, sabe, me sinto tão bem quando tô fazendo essas coisas pelos otros, porque eu me sinto bem, me sinto feliz de estar vendo todas as coisas voltando, então, isso me, me dá alegria, sabe, eu ainda penso longe, se deus quiser nós vamo chegá muito longe, vão ouvir falá muito da gente, ainda [...] 
Diferente de Aline, Vanessa encontra no seu trabalho da reciclagem uma forma de reconhecimento social, que extrapola o grupo de catadores e os limites geográficos do seu local de moradia. Quando a entrevistada retrata a reciclagem faz tanto referência ao trabalho do passado, como também à sua atividade à época da entrevista - Vanessa trabalhava na área financeira de uma das 17 Unidades de Triagem que atuam no mercado da reciclagem em Porto Alegre. Essa passagem revela, entre outros aspectos, a vontade da entrevistada de apresentar cada vez mais o seu trabalho, motivo de orgulho.

Se no que tange a interpretação encontramos tais diferenças entre as entrevistadas, no que corresponde ao uso de determinados discursos foi possível evidenciarmos semelhanças e repetições importantes: Vanessa também sobrepõem os aspectos positivos da atividade aos negativos, buscando valorizar o seu trabalho diante da entrevistadora, fazendo uso, igualmente, de discursos de cunho moral envolvendo a sobrevivência, a ajuda à família, a obtenção de renda e o consumo. Vale a pena frisarmos, que não se trata de questionar a veracidade desses discursos, mas sim chamar à atenção para a maneira como elas apresentam a atividade, e sobre quais elementos destacam em detrimento de outros, possivelmente, tão importantes biograficamente quanto os que ganharam relevância discursiva.

\section{A interpretação do próprio cargo pelos chefes de gabinete}

Assim como em Rinaldi (2018), a pesquisa citada nesta seção refere-se a um projeto de mestrado, neste caso, voltado para a compreensão dos papéis exercidos pelo cargo de chefia de gabinete em âmbito legislativo municipal ${ }^{19}$. Foram analisadas, ao total, quatro entrevistas, sendo três semi-estruturadas e uma entrevista de narrativa biográfica, realizadas com chefes de gabinete de diferentes perfis ideológicos e partidários. As entrevistas foram conduzidas nos gabinetes parlamentares da Câmara de Vereadores em que os informantes trabalhavam à época. No momento da entrevista, deixou-se claro qual era o interesse de pesquisa da entrevistadora.

Durante as entrevistas, muitas informações acerca do background familiar foram expostas. Um dos entrevistados afirmava reconhecer a si próprio como alguém que teria se envolvido com a política por meio de influências familiares, citando o pai, que era admirador de um partido político de direita. Ele teria se criado com essa mesma formação. Os entrevistados constantemente conferem significados, ao olhar para seus antepassados, acerca de seu momento presente. Por isso, temáticas como o processo de entrada dos indivíduos na política e os significados que conferem a sua participação, foram centrais para a análise da pesquisa.

Nas conclusões acerca da entrada dos indivíduos na política e os significados sobre sua participação, identificou-se através da análise das entrevistas e do suporte teórico de autores como Pereira e Mourão (2014), Rosenthal (2014) e Alcântara (2016), que são múltiplos os elementos que influenciam nesse envolvimento. Dentre eles, destaca-se, em primeiro lugar, a estrutura biográfica

\footnotetext{
19 Ver CARDOSO, Suliane. Quem são eles? Os bastidores da política e a diversidade de papéis dos chefes de gabinete. Dissertação (Mestrado em Ciências Sociais) - Programa de Pós-Graduação em Ciências Sociais, Pontifícia Universidade Católica do Rio Grande do Sul (PUCRS), Porto Alegre, 2019.
} 
e familiar ${ }^{20}$, uma vez que esta cria condições propícias para o engajamento através dos primeiros contatos com valores, práticas e hábitos, além da idealização e romantização da trajetória de vida dos antepassados, fazendo com que os indivíduos assumam as trajetórias de pais e avós/avôs, ou de outros, como sendo de relevância biográfica para si mesmos.

O segundo elemento com maior recorrência é o acesso à informação, fosse através de pessoas (familiares, amigos, professores) ou de experiências em diferentes tipos de espaços: movimentos políticos, experiências profissionais, e através do acompanhamento de notícias de diferentes tipos de mídias, como jornais e televisão, uma vez que esses acessos permitem a internalização de códigos e linguagens de categoria política, que podem vir a agir como representações simbólicas na motivação dos atores, ou mesmo para o seu distanciamento, nos casos em que as interpretações são de caráter negativo (FUKS, 2011). Por esse ângulo, Pereira e Mourão (2012) ponderam que durante o percurso da socialização dos indivíduos, a política pode tornar-se permeada de significações subjetivas, na medida em que o ator social interage através das informações que adquire por meio das experiências vivenciadas.

De acordo com Fuks (2011), pesquisas que têm como objeto o engajamento político dos indivíduos reforçam também a tese de que as vantagens asseguradas por fatores estruturais (recursos, oportunidades, etc.) só são convertidas em participação política quando há motivação individual. Nesse sentido, é possível afirmar que as experiências prévias provenientes de ambientes socializadores como a família, a escola, o emprego, além da motivação individual são alguns dos principais elementos para a análise da construção social dos indivíduos, de seus valores e códigos políticos, assim como das influências sociais que os posicionam em determinados espaços políticos, o que se evidenciou também nos discursos de todos os entrevistados.

Nos discursos elaborados pelos entrevistados, além da análise das vivências, pode-se verificar outros posicionamentos políticos desses informantes. Mesmo quando questionado sobre o histórico familiar, um dos chefes de gabinete entrevistado fez questão de relacionar o relato de momentos passados ao o seu momento presente, comparando a participação política do avô e do pai com o seu próprio envolvimento político, afirmando que ninguém de sua família havia se tornado militante como ele posteriormente se tornou. A mistura entre passado e presente e a comparação com a participação dos pais demonstra que o cargo político que desempenha trata-se de uma zona de interesse do entrevistado, conceito definido por Berger e Luckmann (2002) como os lugares da rotina que se encontram sempre dispostos à atenção dos seres humanos, tais como o trabalho e as suas relações. De acordo com os autores, o cotidiano presente de quem conta uma história, mesmo que sobre o passado, pode surgir com facilidade nos momentos de relato.

No que tange ao modo como o cargo era representado, observou-se que discurso muito comum nas entrevistas tratava-se de que os chefes de gabinete usassem expressões que pudessem demonstrar suas práticas de trabalho não somente como ações individuais, mas sim como resultado de esforços conjuntos. Por isso, quando se falava sobre as responsabilidades exercidas, os entrevistados costumavam usar expressões como "a gente desenvolveu", "nós trabalhamos" ou

20 Fuks (2011) salienta que o debate acerca do papel familiar na aquisição de conhecimento, na formação das atitudes e no padrão de comportamento político reitera, constantemente, que esse campo é considerado como um dos ambientes definidores nesse processo, fazendo com que a participação dos pais tenha efeito direto para o engajamento dos filhos. 
mesmo "o gabinete realizou". Tal discurso pode estar vinculado ao fato de que o trabalho do chefe de gabinete e sua imagem estão, normalmente, extremamente vinculadas a imagem do político. Assim, as ações realizadas pelo assessor são, por consequência, as ações realizadas pelo próprio político. Tal vinculação de imagem é bastante recorrente entre os assessores parlamentares e pôde ser evidenciada entre todos os entrevistados.

Sob a mesma perspectiva, uma característica também recorrente faz referência à legitimação da qualidade do trabalho desenvolvida entre os gabinetes. Era comum que, mesmo quando não fossem questionados sobre o assunto, os entrevistados afirmassem suas percepções acerca do quanto consideram que as atividades desenvolvidas por si mesmos (assim como pelo gabinete $\mathrm{e}$ seus pertencentes), e as dificuldades envolvidas no cargo, eram sacrifícios realizados em prol da sociedade. O discurso desse gênero aparecia com frequência nos relatos sobre suas motivações de entrada, uma vez que diziam, muitas vezes, que a razão que os guiou para o cargo estava envolvido com características como a vontade de ajudar ao próximo.

Além disso, as comparações do cargo exercido com outros locais de trabalho era constante: a maioria afirmava considerar que o gabinete em que trabalhava era diferenciado dos demais. Um dos entrevistados disse que o seu trabalho costumava ser reconhecido inclusive entre outros chefes de gabinete que têm o costume de procurá-lo para pedir auxílio em determinadas tarefas, e que isso acontece mesmo com assessores de posições ideológicas distintas. A constante comparação das atividades com outros colegas de cargo demonstra características da própria ocupação, uma vez no ambiente político existem ocasiões em que os chefes de gabinete de outros partidos e políticos não costumam ser considerados como colegas, mas sim, como oposição.

Acerca dos aspectos referidos, tanto em relação à tentativa de relacionar relatos do passado com o presente, como a busca por demonstrar para o entrevistador, através da fala, a qualidade do trabalho desenvolvido, além da comparação com outros gabinetes, demonstram uma função política de discurso que envolve características tais como a distinção de si em relação aos demais, assim como a legitimação do cargo e das atividades desenvolvidas pelos entrevistados. Desta forma, quando falam que são militantes como os pais não foram, que agem em prol da sociedade, e que seu trabalho é diferenciado, existe uma tentativa de legitimação que acontece em diferentes patamares.

\section{Considerações finais}

A importância da análise da função dos discursos sociais através da biografia se constitui na possibilidade de considerar, como afirma Rosenthal (2014), a interiorização do mundo social pelos sujeitos através de seus conjuntos de experiências e vivências e do modo como os expõem. Argumentamos, primeiramente, que independente da proximidade com o universo político, não são apenas os ditos agentes políticos aqueles que instrumentalizam as representações do mundo social a seu favor, e sim todos os sujeitos que, de uma maneira ou de outra, reproduzem discursos sociais buscando a autolegitimação. Nos casos apresentados, evidenciou-se que os discursos podem se manifestar em diversos sentidos, sendo um deles, por exemplo, o de legitimação do trabalho. No caso das catadoras, percebe-se uma luta por legitimação da atividade, que se encontra em constante conflito 
com a lei. Embora as proibições e restrições, que dificultam o cumprimento da rotina da ocupação não ganhem centralidade nos seus discursos, seguimos a hipótese de que uma supervalorização do seu trabalho estaria relacionada às estratégias de reconhecimento de sua atividade, bem como de si mesmas, num contexto social que é, para elas, extremamente desvantajoso.

No que diz respeito aos chefes de gabinete, a permanência no cargo depende de uma reeleição no período de quatro anos (no caso daquele que segue trabalhando para o mesmo parlamentar). Por isso, os discursos inflamados, que são feitos de modo a demonstrar unidade (reafirmando as qualidades da atividade não somente realizadas pelo próprio assessor, como também pelo parlamentar e pelo gabinete como um todo), podem estar relacionados com um interesse de manutenção do cargo e, portanto, de uma estabilidade profissional. Assim, mesmo que de maneiras distintas, nos foi possível identificar, em ambos os estudos aqui apresentados, um interesse de permanência ou, ao menos, de continuidade de renda e reconhecimento social diante de contextos sociais e interações que podem colocar essa possibilidade em risco. Nos discursos de ambos os casos, partindo da tentativa de defesa de suas ocupações, a função legitimadora do discurso faz-se, portanto, presente.

Com a legitimação surge, então, a questão da estabilização ou "normalização". Se por um lado encontramos discursos que visam a supervalorização de suas práticas, por outro, também se fazem presentes aqueles discursos que remetem à dúvida sobre suas condutas, quando não a um sentimento de culpa vinculada a uma ideia de fracasso. Assim, buscar as teorias e justificativas que possam auxiliar os sujeitos na compreensão de experiências tão complexas e ambíguas é fundamental para termos certeza de que "estamos no caminho certo". Um exemplo deste tipo de manifestação é a maneira como Aline, por exemplo, busca justificar através da sua inserção no trabalho da assistência social, o motivo pelo qual sente vergonha de trabalhar na reciclagem, mesmo sendo tão grata por tudo que a atividade lhe proporcionou. A interpretação dos entrevistados a respeito de suas atividades profissionais demonstrou, de maneira geral, diferentes perspectivas que se apresentam tanto através do caráter positivo, quanto negativo. Quanto à catação, a sua importância é constantemente vinculada à necessidade de sustento familiar e de consumo, assim como para o reconhecimento. Por outro lado, há ocasiões nas quais a vergonha da atividade é também trazida à tona, demonstrando a ambiguidade envolta na interpretação. Já no que tange aos chefes de gabinete, grande parte dos discursos eram significados de modo positivado, no sentido de legitimação do cargo como uma atividade que afirmavam ser realizada "em prol da sociedade" a fim de que pudessem "ajudar o próximo". O mesmo tipo de discurso aparece na entrevista com uma catadora, quando a mesma afirma se sentir bem em "fazer (trabalhar) pelos outros". Nesse sentido, legitimar também significa estabilizar, tornando toda e qualquer prática, conduta, trajetória ou biografia, normal e acessível à experiência humana. Considerando ainda que o próprio ato de construirmos nossa biografia configura um momento no qual estamos presos a formalidades, valores e regras sociais de todo o tipo, mas também suscetíveis à reflexão acerca destas certezas, reforça a importância da função legitimadora dos discursos sociais, os quais têm o poder de assegurar o sentido mesmo quando este corra o risco de faltar.

Por fim, tais conclusões não teriam sido possíveis sem uma base conceitual que nos auxiliasse na teorização dos fenômenos encontrados no campo empírico. Para tanto, recorremos à compre- 
ensão de Pierre Bourdieu (1989) sobre a função política dos discursos sociais e, com isso, sobre os mecanismos que determinam a estruturação do mundo social. Se analisarmos as entrevistas levando em consideração a maneira como os entrevistados estruturam suas falas e apresentações sobre a atividade, encontramos uma série de mecanismos que se assemelham àquilo que Bourdieu (2007) chamou de luta simbólica. Mas foi com base na teoria de Alfred Schütz (2004; 2018), sobre o sentido da ação, que acreditamos melhor compreender, a nível da interação humana, as dinâmicas presentes na disputa de sentido pelas categorias sociais. Nesse sentido, entendemos nossa tentativa de aproximar ambas as concepções como uma forma de extrair aquilo com maior valor explicativo para a compreensão dos fenômenos revelados em campo, portanto: enquanto Bourdieu nos ajuda a compreender como as categorias sociais e, com elas, os discursos, vão determinando a ação dos sujeitos e suas crenças de forma mais generalista, com Schütz, melhor logramos compreender como essa disputa de sentido ocorre nas relações sociais, apontando tanto para os mecanismos que levam à reprodução, mas também para aqueles que possibilitam a criatividade, quando não, até mesmo, a inovação.

\section{REFERÊNCIAS}

ALCÂNTARA, Manuel. A profissionalização da política. Curitiba: CPOP -PPGCP/UFPR, 2016. BERGER, Peter; LUCKMANN, Thomas. A construção social da realidade. Petrópolis: Vozes, 2002. BOURDIEU, Pierre. A ilusão biográfica. In: AMADO, Janaína; FERREIRA, Marieta de Moraes (org.). Usos e abusos da história oral. 8. ed. Rio de Janeiro: Editora FGV, 2006, p. 183-191.

BOURDIEU, Pierre. O poder simbólico. Lisboa: Difel, 1989.

BOURDIEU, Pierre. A Miséria do Mundo. Petrópolis: Vozes, 2001.

BOURDIEU, Pierre. A distinção: crítica social do julgamento. Porto Alegre: Zouk, 2007.

BOURDIEU, Pierre. Meditações Pascalianas. Rio de Janeiro: Bertrand Brasil, 2001.

BRASIL. Lei n 12.305 , de 2 de agosto de 2010. Institui a Política Nacional de Resíduos Sólidos. Diário Oficial da União: seção 1, Brasília, DF, ano 189, n. 3, p. 1-84, 3 ago. 2010.

CAMPANI, Darci Barnech. A política nacional de resíduos sólidos e a sustentabilidade de nossa sociedade.In: AMARO, Aurélio Bandeira; VERDUM, Roberto (org.). Política Nacional de Resíduos Sólidose suas interfaces com o espaço geográfico: entre conquistas e desafios. Porto Alegre: Letral, 2016, p. 13-21. https://doi.org/10.21826/9788563800237

CARDOSO, Suliane. Quem são eles? Os bastidores da política e a diversidade de papéis dos chefes de gabinete. Dissertação (Mestrado em Ciências Sociais) - Programa de Pós-Graduação em Ciências Sociais, Pontifícia Universidade Católica do Rio Grande do Sul, Porto Alegre, 2019.

DUKUEN, Juan. Entre Bourdieu y Schutz. Encuentros y desencuentros en fenomenología social. Revista Latinomaericana de Estudios sobre Cuerpos, Emociones y Sociedad, [s. l.], n. 3, ano 2, p. 39-50, ago. 2010.

DIAS, Allan Rodrigues. Condições de vida, trajetórias e modos de "estar" e "ser" catador: estudo de trabalhadores que exercem atividade de coleta e venda de materiais recicláveis na cidade de 
Curitiba (PR). 2002. 102 f. Dissertação (Mestrado em Psicologia Social) - Faculdade de Psicologia, Universidade de São Paulo, São Paulo, 2002. https://doi.org/10.11606/d.47.2002.tde-06102005-132201 FUCKS, Mário. Efeitos diretos, indiretos e tardios: trajetórias da transmissão intergeracional da participação política. Lua Nova, São Paulo, n. 83, p. 145-178, 2011. https://doi.org/10.1590/s0102$\underline{64452011000200006}$

MICHELOTTI, Fernando C. Catadores de "lixo que não é mais lixo": um estudo da dimensão do reconhecimento social a partir de sua experiência de organização coletiva no Rio Grande do Sul. 2006. 192 f. Dissertação (Mestrado em Sociologia) - Universidade Federal do Rio Grande do Sul, Porto Alegre, 2006.

PAPE, Elise. Der biographische Ansatz in Frankreich:Entstehung und aktuelle Entwicklungen. BIOS, Jg. 22, 2009, Heft 2, p. 283 -292. https://doi.org/10.1007/978-3-658-21831-7 60

PEREIRA, Jesus; MOURÃO, Pedro Jorge. Os ancestrais e a infância: elementos primários da formação do habitus políticos. Revista Opsis, Catalão , v. 12, n. 1, p. 90-106, 2012. https://doi.org/10.5216/o. v12i1.17383

PORTO ALEGRE. Decreto $n^{\circ}$ 16.638, de 9 de março de 2010. Regulamenta a Lei $n^{\circ}$ 10.531, de 10 de setembro de 2008, que institui, no Município de Porto Alegre, o Programa de Redução Gradativa de Veículos de Tração Animal (VTAs) e de Veículos de Tração Humana (VTHs). Porto Alegre: SIREL, 2010.

PORTO ALEGRE. Departamento municipal de limpeza urbana. Unidades de triagem. [2018?]. Disponível em: http://www2.portoalegre.rs.gov.br/dmlu/default.php?p_secao=113. Acesso em: 3 maio 2019.

RINALDI, Débora. A interpretação da catação pelos catadores: um estudo biográfico 2018. 169 f. Dissertação (Mestrado em Ciências Sociais) - Programa de Pós-Graduação em Ciências Sociais, Pontifícia Universidade Católica do Rio Grande do Sul, Porto Alegre, 2018.

ROSENTHAL, Gabriele; FISCHER-ROSENTHAL, Wolfram. Warum Biographieanalyse und wie man sie macht. Zeitschrift für Sozialisationsforschung und Erziehungssoziologie (ZSE). n. 1, p. $405-$ 427, 1997.

ROSENTHAL, Gabriele. Pesquisa social interpretativa: uma introdução. 5. ed. Porto Alegre: EDIPUCRS, 2014.

SANTOS, Hermílio. Ação, Relevância e Interpretação Subjetiva. Pernambuco: Estudos de Sociologia, 2012. Disponível em: https://periodicos.ufpe.br/revistas/revsocio/article/view/235228/28252. Acesso em: 14 ago. 2019.

SCHÜTZ, Alfred. Der sinnhafte Aufbau der sozialen Welt: Eine Einleitung in die verstehende Soziologie. Konstanz: UVK, 2004. 500s. https://doi.org/10.1007/978-3-7091-3108-4 5

SCHÜTZ, Alfred. A Construção significativa do mundo social: Uma introdução à sociologia compreensiva. Petrópolis: Editora Vozes. 2018.

SILVA, Caroline; NASCIMENTO, Luís Felipe. 25 anos da coleta seletiva de Porto Alegre: história e perspectivas. Revista Gestão e Desenvolvimento, Novo Hamburgo, v. 14, n. 2, p. 33-50, jul./dez. 2017. https://doi.org/10.25112/rgd.v14i2.1135

Recebido: $15 / 02 / 2019$

Aceito: 21/05/2019 


\section{Biografia do Autor}

\section{Débora Rinaldi}

Mestre e doutoranda em Ciências Sociais. ORCID: http://orcid.org/0000-0001-7006-5588; EMAIL: dkleinrinaldi@gmail.com

Instituição: Pontifícia Universidade Católica do Rio Grande do Sul.

Localização: Av. Ipiranga, 6681 -Partenon - Porto Alegre/RS

\section{Suliane Cardoso}

Mestre e doutoranda em Ciências Sociais. ORCID: http://orcid.org/0000-0002-3945-4427; EMAIL: sulianecardoso@gmail.com

Instituição: Pontifícia Universidade Católica do Rio Grande do Sul.

Localização: Av. Ipiranga, 6681 -Partenon - Porto Alegre/RS 